\title{
Human Brucellosis in the Republic of Macedonia by Regions Depending on Vaccination Procedures in Sheep and Goats
}

\author{
Zharko Stojmanovski ${ }^{*}$, Milka Zdravkovska ${ }^{2}$, Vaso Taleski ${ }^{2}$, Svetlana Jovevska ${ }^{2}$, Velo Markovski ${ }^{2}$ \\ ${ }^{1}$ Food and Veterinary Agency, Branch Office Kumanovo, Kumanovo, Republic of Macedonia; ${ }^{2}$ Goce Delchev University, \\ Faculty of Medical Sciences, Shtip, Republic of Macedonia
}

\begin{abstract}
Citation: Stojmanovski Zh, Zdravkovska M, Taleski V, Jovevska S, Markovski V. Human Brucellosis in the Republic of Macedonia by in So De in Sheep and Goats. Maced J Med Sci. 2014 http://dx.doi.org/10.3889/MJMS.1857-5773.2014.0363. Key words: human brucellosis; brucellosis in sheep and goats; brucellosis vaccination Republic of Macedonia.

"Correspondence: Zharko Stojmanovski. Food and Veterinary Agency, Branch Office Kumanovo, 11 Oktomvri str, bb, 1300 Kumanovo, Republic of Macedonia. E-Mail: zarkostojmanovski@yahoo.com

Received: 23-Sep-2013; Revised: 30-Jan2014; Accepted: 08-Feb-2014; Online first: 2014; Accep

Copyright: (๑) 2014 Stojmanovski et al. This is an open-access article distributed under the terms of the Creative Commons Attribution License, which permits unrestricted use, distribution, and reproduction in any medium, provided the original author and source are credited.

Competing Interests: The authors have declared that no competing interests exist.
\end{abstract}

\begin{abstract}
Background: Besides the strategy based on test-and-slaughter policy for seropositive sheep and goats after an evaluation of the situation, vaccination measure of those animals against brucellosis
\end{abstract} with Rev 1 vaccine in 2008 have been implemented.

Aims: To examine the influence of the new measure for control and eradication of brucellosis in sheep and goats on the incidence of human brucellosis before and after vaccination with $B$. melitensis Rev.1.

Material and methods: This is a retrospective study in which comparison of the incidence of human brucellosis in the three regions has been made depending on the vaccination procedure in sheep and goats one year before the implementation of the vaccination (2007) and 4 years later. Data for the infected sheep and goats were obtained from the Food and Veterinary Agency and data for human brucellosis were obtained from the Institute of Public Health of the Republic of Macedonia.

Results: The greatest decrease in the incidence of human brucellosis (from 124.3 to $19.7 / 100,000$ inhabitants) was registered in the region 3 where mass vaccination of sheep and goats was conducted. The highest incidence rate of brucellosis in sheep and goats was registered in 2007 (2010/100,000 sheep and goats) and the lowest in 2011 (156/100,000 sheep and goats). Periodic prevalence of brucellosis in sheep and goats prior to vaccination was 6882/100,000 sheep and goats and after vaccination $3698 / 100,000$ sheep and goats $(p<0.05)$. There was a moderate positive correlation between the number of infected individuals with brucellosis and the number of infected sheep and goats $(r=0.26)$.

Conclusion: Decline of the incidence of human brucellosis is one of the major indicators for successfully implemented new control programs and strategies for prevention and eradication of brucellosis in sheep and goats. Vaccination was good measure to control brucellosis in the 3 regions.

\section{Introduction}

According to the World Health Organization (WHO) brucellosis is zoonotic infection with a worldwide impact, contributing to significant health and economic problems [1].

Brucellosis is considered to be one of the main zoonotic diseases in Republic of Macedonia. The number of reported human infections has not decreased significantly despite the eradication programme (test and slaughter) in cattle, sheep and goats [2].

The Brucella melitensis (B. melitensis) Rev-1 strain is currently considered as the best vaccine available for the control of ovine and caprine brucellosis, especially when used at the standard dose by the conjunctival route [2].

During the period from 1980 to 2009 approximately 11,000 cases of human brucellosis 
were registered in Republic of Macedonia, with a median annual morbidity of $20 / 100,000$ population [3].

Control strategies available to prevent human brucellosis are pasteurization of milk, livestock vaccination and elimination of infected animals. In animal populations, control of infection can be based on different strategies which selection depends on numerous factors. Mass vaccination is crucial for the control and eradication of bovine, ovine and caprine brucellosis but other complementary measures that may need consideration include improved farm hygiene, restriction and control of trade and movement of animals, testing of animals and isolation and removal of infected animals [4].

Brucellosis belongs to the group of infectious diseases that is distributed all over the world due to the possibility of its rapid spreading. This infection is important for the economy of each country and its public health significance is emphasized even more by the large loss of livestock, long-term treatment of infected people and long-lasting fight for its eradication [5].

Brucellosis remains an important public health problem in the Mediterranean region where the efforts for eradication of Brucella melitensis in animals have failed [6].

Over the last few decades the onset of this zoonosis has been considerably changed on a global level due to the implementation of different sanitary, socioeconomic and political measures as well as due to the evolution of international transport [7].

Brucellosis is an occupational hazard. Diary workers, shepherds, veterinarians, butchers, laboratory workers and animal husbandry personnel are at a higher risk $[8,9]$.

In the last 2-3 decades each year the Government of the Republic of Macedonia establishes the Program for examination of the onset, prevention and elimination of human brucellosis, which grants finances for implementation of the recommended measures and finances for education of the population. The ten Public Health Centers (PHC) have been appointed to implement these measures in practice [10].

In the period from 2007 to September 2009, 113 blood cultures from patients with diagnosis of brucellosis hospitalized at the University Infectious Diseases and Febrile Condition Clinic in Skopje, Republic of Macedonia, were examined. A total of 16 blood cultures from different patients were positive (14.2\%), showing Gram negative bacilli, oxidase positive small colonies on Columbia agar media. The isolates were identified as four biochemically different types of $B$. mellitensis [11].

Brucellosis in small ruminants caused by $B$. melitensis is continuously causing great loses in Macedonian livestock production [2]. The prevalence of brucellosis in sheep and goats (B. melitensis, biovar 2) for a period of 30 years was less than $2 \%$. Brucellosis in cattle is limited to sporadic cases, especially where cattle cohabit with sheep and goats [12].

In 2008, after an evaluation of the situation, the Veterinary Directorate introduced new programme for control of brucellosis in small ruminants. The selection of the strategy was based on the epidemiological situation in the country, the resources available both financial and human, recommendations in the literature and experiences of different countries in combating the disease. The existing data in 2008 showed that the most eastern region is traditionally free of the disease (the disease was never confirmed or only isolated outbreaks reported). At the same time there is a region consisting of several municipalities where the disease prevalence both on flock and individual animal level is very high. The largest part of the territory of Republic of Macedonia situation had moderate flock prevalence with regard to brucellosis [2].

Republic of Macedonia has introduced the vaccination program of sheep and goats against brucellosis using the Rev 1 vaccine in 2008 (Fig. 1) [13].

In the period 2007-2011, 2741 cases of cattle brucellosis were registered (total number of conducted tests were 785 392) and the positive animals were slaughtered [14]. Vaccination of cattle against brucellosis is not allowed/is forbidden.

\section{Material and Methods}

Vaccination program of sheep and goats with the $B$. melitensis strain Rev. 1 conjunctival vaccine has been introduced in the Republic of Macedonia in 2008. Each dose contains 1 to $2 \times 10^{9} \mathrm{CFU}$. The country has been divided into three regions in line with the procedure for the administration of the vaccine (Fig. 1).

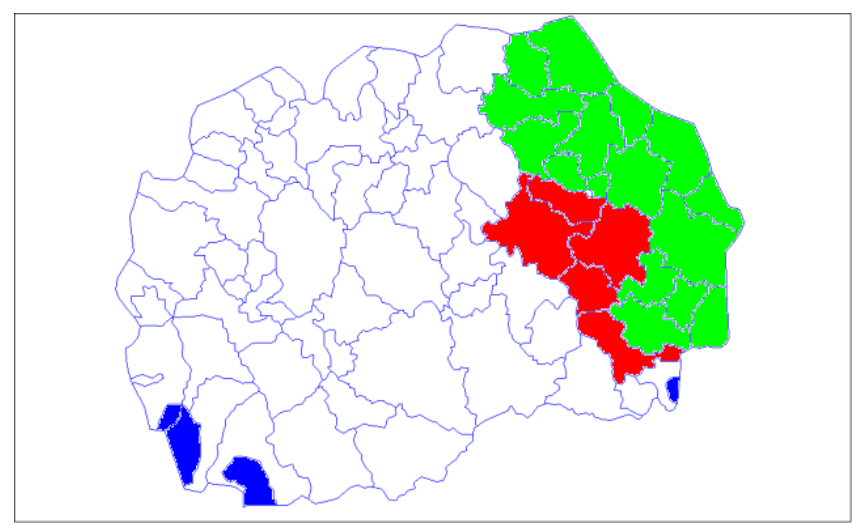

Figure 1: Territory of the Republic of Macedonia divided into three regions in line with the procedure for the administration of the vaccine against brucellosis in sheep and goats in 2008. Region 1: green color - forbidden vaccination (unvaccinated region), Region 2: White color - vaccination of small ruminants aged 3-6 months, Region 3: Red color - mass vaccination. 
In region 1 where sheep and goats' vaccination is forbidden, a total of 16 municipalities (Berovo, Pehchevo, Delchevo, Makedonska Kamenica, Vinica, Kochani, Zrnovci, CheshinovoObleshevo, Kratovo, Kriva Palanka, Rankovce, Probishtip, Strumica, Bosilevo, Vasilevo and Novo Selo) along the border with R. Bulgaria have been included. This region has a total of 258,080 inhabitants and livestock of 155,475 sheep and goats. In the year 2010 vaccination of lambs and kids aged 3-6 months has been started in 2 municipalities, Strumica and Novo Selo.

In region 2 vaccinations of lambs and kids aged 3-6 months is conducted, while the adult animals are tested and if they prove to be positive, they are slaughtered. This region comprises 54 municipalities (Bitola, Mogila, Novaci, Veles, Gradsko, Chashka, Gevgelija, Bogdanci, Dojran, Gostivar, Vrapchishte, Mavrovo and Rostushe, Debar, Centar Zhupa, Demir Hisar, Kavadarci, Rosoman, Kichevo, Vraneshtica, Drugovo, Zajas, Oslomej, Krushevo, Kumanovo, Lipkovo, Staro Nagorichane, Makedonski brod, Plasnica, Negotino, Demir Kapija, Ohrid, Debarca, Prilep, Dolneni, Krivogashtani, Resen, Sveti Nikole, Lozovo, Skopje, Zelenikovo, Ilinden, Petrovec, Sopishte, Studenichani, Chucher Sandevo, Arachinovo, Struga, Vevchani, Tetovo, Brvenica, Tearce, Zhelino, Jegunovce, Bogovinje) with $1,668,989$ inhabitants and 636,596 sheep and goats. In 2010 due to the risk of brucellosis spread among the livestock, a mass vaccination has been conducted in 16 municipalities in the north-west area of $R$. Macedonia bordering Kosovo and Albania, as well as in 16 villages and 14 flocks of sheep and goats in other municipalities.

In region 3 where mass vaccination of sheep and goats has been realized, 5 municipalities (Shtip, Karbinci, Radovish, Konche and Valandovo) with a total of 96,560 inhabitants and 88,336 sheep and goats have been comprised.

The incidence of human brucellosis was monitored one year before vaccination implementation (2007) and four years (2008-2011) after vaccination of small ruminants in all three regions in the Republic of Macedonia.

An analysis has been made of the distribution of registered cases of brucellosis among sheep and goats by regions in line with the regional authorities of the 10 Public Health Centers (PHC) in the Republic of Macedonia in the period from 2003 to 2009.

Data about the infected people with brucellosis were taken from the register of individual cases as well as monthly and annual reports for infectious diseases prepared by the Epidemiology Department of the Institute for Public Health of $R$. Macedonia and reported by the regional PHC.

Diagnosis of brucellosis in animals is performed In the laboratories of the Faculty of
Veterinary Medicine in Skopje using serological tests (Rose Bengal Tests, Complement Fixation Test, ELISA and AGID), isolation of the bacteria and molecular tests (PCR, Genotyping), and it is realized according to the Attachment 1 - Diagnostic tests included in the Program for control and eradication of brucellosis in sheep announced in 2008 and revised in 2010. Data for the infected sheep and goats were obtained from Food and Veterinary Agency of Republic of Macedonia.

Data on the number of sheep and goats in the regions 1, 2, and 3 were obtained by the State Statistical Office of Republic of Macedonia according to the Agriculture Census of the year 2007.

The statistical analysis was done using Statistica 7 software. Values of $p<0.05$ were considered statistically significant.

\section{Results}

In the period 1999-2011, 118,643 cases of brucellosis among sheep and goats were registered (total number of conducted tests were $7,628,886$ ) and the positive animals were slaughtered or destroyed.

The highest incidence (morbidity) of brucellosis among sheep and goats was registered in the year 2007 (2010 positive of 100,000 sheep and goats) and the lowest in the year 2011 (156/100,000). Periodic prevalence for the investigated period was $6882 / 100.000$ before vaccination and 3698/100,000 after start of sheep and goats vaccination (Table 1).

Table 1: Incidence rate of brucellosis among sheep and goats in R. Macedonia during 1999-2011.

\begin{tabular}{ccccc}
\hline Period & $\begin{array}{l}\text { Total } \\
\text { number of } \\
\text { sheep } \\
\text { and goats }\end{array}$ & $\begin{array}{l}\text { Brucellosis } \\
\text { in sheep } \\
\text { and goats }\end{array}$ & $\begin{array}{l}\text { Incidence/100.000 } \\
\text { sheep and goats }\end{array}$ & $\begin{array}{l}\text { Periodic } \\
\text { prevalence } \\
\text { per } 100.000\end{array}$ \\
\hline 1999 & 1288733 & 2116 & 164 & Before \\
2000 & 1250686 & 2026 & 161 & vaccination \\
2001 & 1285099 & 4059 & 315 & $6882 / 100000$ \\
2002 & 1233830 & 10102 & 818 & sheep and \\
2003 & 1239330 & 7029 & 567 & goats \\
2004 & 1432369 & 15413 & 1076 & \\
2005 & 1306190 & 13141 & 1006 & \\
2006 & 1312380 & 13493 & 1028 & After \\
2007 & 943988 & 18978 & 2010 & vaccination \\
2008 (vacc) & 949621 & 16853 & 1774 & $3698 / 100000$ \\
2009 (vacc) & 849372 & 11256 & 1325 & sheep and \\
2010 (vacc) & 854112 & 2865 & 335 & goats \\
2011 (vacc) & 839408 & 1312 & 156 & \\
& & & &
\end{tabular}

Analysis with Pearson's coefficient of correlation has shown a moderate positive correlation between the number of infected people and the number of infected sheep and goats in the investigated period ( $r=0.22, p=0.4003$ ) (Fig. 2). 


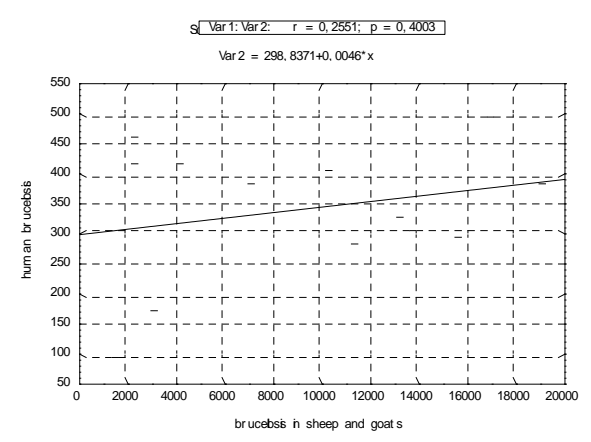

Figure 2: Correlation of brucellosis in sheep and goats and human brucellosis in R. Macedonia for the period 1999-2011.

In the period between 1999 and 2011 an increasing tendency of brucellosis among sheep and goats was observed (Fig. 3).

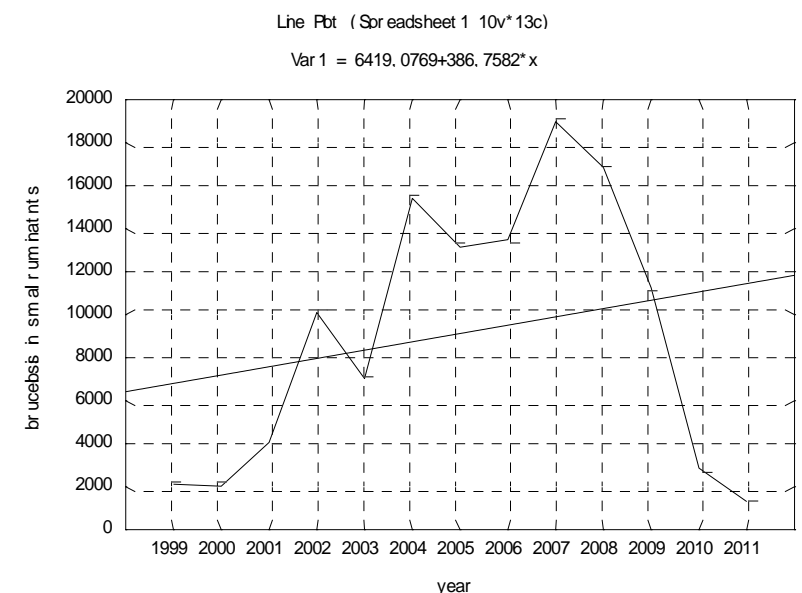

Figure 3: Trend of brucellosis in sheep and goats in Republic of Macedonia during 1999-2011.

Four years after implementation of mass vaccination of sheep and goats versus one year before vaccination (2007), the highest decline in the incidence rate of human brucellosis from 124.3 to $19.7 / 100,000$ inhabitants (84\% decline) was reported in region 3 (Table 2).

Table 2: Incidence of human brucellosis by regions in line with the procedure of the administration of the vaccine in sheep and goats.

\begin{tabular}{lccc}
\hline $\begin{array}{l}\text { Period: } 2007 \\
\text { Before } \\
\text { vaccination }\end{array}$ & Reg 1 & Reg 2 & Reg 3 \\
& $6.97 / 100000$ & $13.8 / 100000$ & $124.3 / 100000$ \\
\hline Period: & 32.1 & & \\
2008 & 14.3 & 18.5 & 101.6 \\
2009 & 14.7 & 12.3 & 45.6 \\
2010 & 7.8 & 5.3 & 43.5 \\
2011 & 3.4 & 19.7 \\
\hline
\end{tabular}

In region 1 increase from 6.97 to $7.8 / 100,000$ inhabitants in the incidence rate $(11.9 \%$ increase) of human brucellosis was observed However, there was a mild decline in the incidence rate of human brucellosis in this region year by year (2008-2011) (Table 2).

In region 2, the largest region by territory, inhabitants and sheep and goats population, there was decline from 13.8 to $3.4 / 100,000$ inhabitants ( $74.5 \%$ decline) of the incidence of human brucellosis after four-year vaccination of the young ruminants (lambs and kids) in comparison with 2007 (Table 2).

Figure 4 illustrates the regional distribution of registered cases of brucellosis in sheep and goats in R. Macedonia, for the period 2003-2009, presented by the 10 Public Health Centers. The largest number of infected sheep and goats was registered in the region of the PHC Shtip - 26\%, followed by PHC Tetovo $16 \%$ and PHC Skopje - 11\%, and the smallest number in the region of PHC Kochani $-1 \%$.

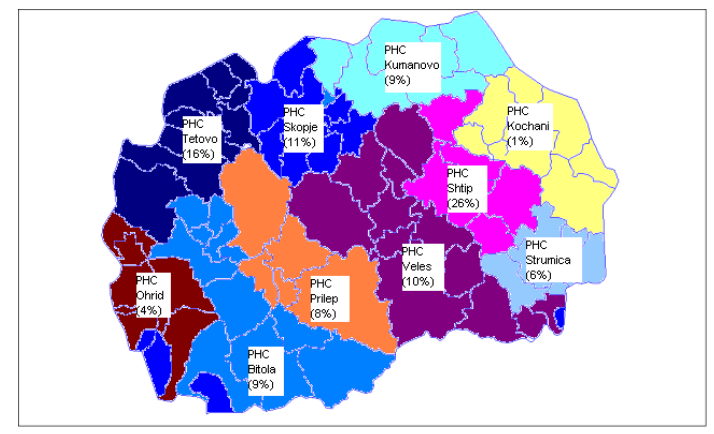

Figure 4: Distribution of registered cases of brucellosis in sheep and goats by regions of the 10 Public Health Centers during 20032009.

\section{Discussion}

During the period 1999-2011 an increasing trend of brucellosis among sheep and goats in R. Macedonia was observed. It is assumed that the real number of infected sheep and goats was significantly larger than the registered one due to the unregistered cases. This is a result of the low level of awareness and education of the stock raisers about the importance of the health status of their herds concerning brucellosis. Insufficient control over the movements of herds from one region to another, movements to regions with unknown status of brucellosis, illegal and/or inadequately controlled trade of live animals and poor safety conditions in some regions of the country in 2001 brought to mass spreading of the disease among small ruminants. The central database for identification and registration of sheep and goats was created in 2008. Prior to this period, identification of sheep and goats with ear tags was inadequate because of the quality of the brands that might fall off and are difficult to read, which leads to a greater risk of flaws in excluding the positive sheep and goats from the herds.

The analysis has shown a moderate positive correlation $(r=0.26)$ between human brucellosis and brucellosis among small ruminants during the period 1999-2011 while in another study conducted for the period 2008-2011 the correlation between human brucellosis and brucellosis among small ruminants was very strong $(r=0.98)$ [15]. This difference in the correlation might be a result of the conducted 
activities for protection and education of the population by the health personnel of the Public Health Centers as well as by the other relevant health and veterinary institutions in the country.

Analysis of the incidence of human brucellosis has revealed the greatest decline in region 3 where mass vaccination of sheep and goats was conducted. The effects of vaccination against brucellosis of small ruminants were also investigated in Greece and similar results were obtained [16].

The larger part (Berovo, Delchevo, Pehchevo, Makedonska kamenica, Kratovo) of region 1 is considered to be traditionally free of the disease (the disease was never confirmed or only isolated outbreaks reported). Additionally, the geographical position of this region has to be taken into consideration, too. It borders with Bulgaria, a country free from Brucella melitensis until 1958 (although during 2005-2007 its re emergence was recorded) [17]. Mild increase of the incidence of human brucellosis has been observed. This is very likely a result of the low level of awareness and education of the animal breeders, who did not respect the legislation regulations for movement control of sheep and goats including obtaining an official certificate for the health status of the flock. This is especially valid for the Strumica region, which is by geographical location, trade, market and by communication tightly connected with Radovish and Valandovo, municipalities with a high incidence of human and animal brucellosis. In fact, the largest number of registered human brucellosis in the examined period was from the Strumica region.

There was a decreased incidence rate of human brucellosis in the largest region 2, after the 4year vaccination of the lambs and kids and after implementation of mass vaccination in some municipalities and villages in the year 2010, similar results were obtained in Western Greece [18]. This might be a result of the implementation of the vaccination program and concomitant control of movements of sheep and goats in comparison to other regions.

Distribution of brucellosis among sheep and goats in the relevant regions of the $10 \mathrm{PHC}$ in $\mathrm{R}$. Macedonia (for the period 2003-2009) was similar to the distribution of human brucellosis for the period 1999-2009 [19]

\section{Recommendations}

- To evaluate and revise the programs for control and eradication of brucellosis in animals, comprising vaccination and testing of sheep and goats as well as slaughtering of infected animals. These programs have to be designed on the basis of total incidence rate of the disease in animals and in accordance to the local epidemiology of the disease in animals and humans.
To enhance veterinary resources (technical, financial and human).

- More efficient and more rigorous movement control of sheep and goats and regular maintenance of the identification and registration system of sheep and goats.

- To create a unique system for rapid information on the onset of zoonoses (including brucellosis) available to the authorized governmental institutions in the field of veterinary and public health.

\section{References}

1. Boschiroli ML, Foulongne V, O'Callaghan D. Brucellosis: a worldwide zoonosis.Curr Opin Microbiol. 2001;4:58-64.

2. Kirandziski T, Nikolovska G, Nakova E, Smilenovska B, Stojmanovska B, Naletoski I, et al. Brucellosis control in small ruminants in the Republic of Macedonia. Contributions. 2010; 31(1):181-90.

2. Garin-Bastuji B, Blasco JM, Grayon M, Verger JM. Brucella melitensis infection in sheep: present and future. Vet Res. 1998,29 :255-274.

3. Nikolovski B, Karadzovski Z, Kostovska J. 30 Years of Brucellosis in the Republic of Macedonia: Experience with its Prevalence, Prevention and Control. Maced $\mathrm{J}$ Med Sci.2010;3(3):263-267.

4. Smits H, Kadri M. Brucellosis in India: a deceptive infectious disease. Indian J Med Res. 2005, 122:375-384.

5. Almuneef MA, Memish ZA, Balkhy $\mathrm{HH}$, Alotaibi B, Algoda S, Abbas $M$, et al. Importance of screening household members of acute brucellosis cases in endemic areas. Epidemiol Infect. 2004;132:533-40.

6. German V, Papadopoulos N, Diakalis C, Goritsas C, Ferti A. Case report. Paravertebral abscess and neurological deficits in cervical brucellar spondylitis. Eastern Mediterranean Health Journal. 2010;16:4.

7. Pappas G, Akritidis N, Bosilkovski M, Tsianos E. Medical progress-brucellosis. N Engl J Med. 2005;352:2325-36.

8. Agasthya AS, Isloor S, Prabhudas K. Brucellosis in high risk group individuals. Indian J Med Microbiol. 2007;25:28-31.

9. European commission. Health and Consumer Protection Directorate General. Directorate C- scientific health opinions. Title: Brucellosis in Sheep and Goats (Brucella melitensis). Report Adopted 12 July 2001.

10. Government of the Republic of Macedonia, Programme for investigation, control and eradication of human brucelloisis. Official Gazette of the Republic of Macedonia; No. 07/2011, 20/2010, 03/2009.

11. Cekovska Z, Petrovska M, Jankoska G, Panovski N, Kaftandzieva A. Isolation, identification and antimocrobial susceptibility od brucella blood culture isolates. Contributions. 2010;31(1); 117-132.

12. Bosnakovski J, Tetikovic S, Ivanovski N, Hristovski M, Markic Z, Danev M. Epizootic picture of brucellosis in the Republic of Macedonia. Macedonian Veterinary Review.1992;21(1): 75-8.

13. Government of the Republic of Macedonia, Program for control and eradication of sheep and goats brucellosis. Official Gazette of the Republic of Macedonia; No.59/2008: 2-13.

14. Food and Veterinary Agency of the Republic of Macedonia. Annual reports. Available at: www.fva.gov.mk 
15. Stojmanovski Zh. Some epidemiological aspects of human brucellosis after introduction of sheep and goats vaccination. [In Macedonian]. Vox Medici. 2013; 78:235-8.

16. Minas A, Minas M, Stournara A, Tselepidis S: The "effects" of Rev-1 vaccination of sheep and goats on human brucellosis in Greece. Prev Vet Med. 2004; 64:41-47.

17. Russo G, Pasquali $P$, Nenova $R$ et al. Reemergence of human and animal brucellosis,Bulgaria. Emerging Infectious Disease. 2009; 15:2.

18. Jelastopulu E, Bikas Ch, Petropoulos Ch, Leotsinidis M. Incidence of human bruceloosis in a rural area in Western Greece after the implementation of a vaccination programme against anima brucellosis. BMC Public Health. 2008; 8:241.

19. Zdravkovska M, Stojmanovski Zh, Taleski V, Jovevska S, Markovski V. Public Health Aspects of Human Brucellosis in the Republic of Macedonia. Maced J Med Sci. 2013; 6(4):446-449. 